\title{
PROPOSTA DE IMPLEMENTAÇÃO DE UM SISTEMA DELIVERY COM DIFERENCIAL COMPETITIVO: ESTUDO DE CASO MERCADINHO SILVA
}

\section{ARTIGO ORIGINAL}

CARVALHO, Alessandra Glória de ${ }^{1}$

AGUILA, Carlos Alberto Arévalo Del ${ }^{2}$

OLIVEIRA, Daniel Barroso de ${ }^{3}$

ROBERTO, José Carlos Alves ${ }^{4}$

CARVALHO, Alessandra Glória de. Et al. Proposta de Implementação de um sistema delivery com diferencial competitivo: Estudo de Caso Mercadinho Silva. Revista Científica Multidisciplinar Núcleo do Conhecimento. Ano 05, Ed. 11, Vol. 01, pp. 54-75. Novembro de 2020. ISSN: 2448-0959, Link de acesso: https://www.nucleodoconhecimento.com.br/administracao/sistema-delivery

\section{RESUMO}

A abordagem do conteúdo a ser apresentado, busca demonstrar de forma estratégica a capacidade e expressividade que a diversificação dos canais de distribuição alcança ao ser aplicada, o presente estudo surgiu a partir da verificação das áreas críticas efetuadas na empresa Mercadinho Silva que atua no segmento de Comércio e Serviço de Alimentos em Manaus, onde a partir da coletas de dados e análise do conteúdo

\footnotetext{
${ }^{1}$ Graduando em Administração pelo Centro Universitário Fametro.

${ }^{2}$ Graduando em Administração pelo Centro Universitário Fametro.

${ }^{3}$ Graduando em Administração pelo Centro Universitário Fametro.

${ }^{4}$ Orientador. Mestrado profissional em Engenharia de produção. Especialização em Gestão em Logística empresarial. Graduação em Administração com Ênfase em Marketing.
} 
constatou-se menor desempenho na área do Marketing pela ausência de processos direcionados a distribuição de venda dos produtos. O estudo tem como objetivo: Analisar como os canais de Distribuição podem gerar uma vantagem competitiva para os supermercados de pequeno porte, e como objetivos específicos apresenta: Descrever as estratégias de captação de vantagens competitivas aplicadas aos supermercados de pequeno porte, discutir a diversificação de canais de distribuição como recurso estratégico, formular uma estratégia inovadora para obter vantagens competitivas através da diversificação dos canais de distribuição. A criação dos indicadores para ações interventivas se deu pela necessidade de tratar a área crítica, então foi usada a ferramenta 5W2H para auxiliar na proposta da implementação dos atos de evolução indicados que são: Gerenciamento de conta dos clientes, aplicar um sistema delivery, contratar o serviço delivery, acompanhar o processo logístico das entregas. Após a execução da proposta espera-se que a organização obtenha um nível de competitividade elevada, alcançando a preferência de todos os seus públicosalvo e aplique a implementação das ações de forma responsável para melhoria contínua do estabelecimento.

Palavras-Chave: Canais de distribuição, Sistema Delivery, Diversificação dos Canais, Vantagem Competitiva, Pequenos Negócios.

\section{INTRODUÇÃO}

Com o crescimento da população mundial, o ramo atacadista e varejista vem crescendo cada vez mais. O mesmo crescimento vem sendo observado no ramo de comércio que trabalha diretamente com alimentação. Consequentemente, o aumento da concorrência proporciona várias opções de compra ao consumidor.

Diante de tanta concorrência, a logística ganhou um papel de extrema importância neste processo, deixando de ter um papel de caráter meramente transportador ou entregador e passando a envolver-se em tudo que acontece dentro da empresa. Assim a distribuição pode ser considerada uma continuação da venda,uma vez que tem como função levar o produto ao consumidor final, no qual, geralmente é efetuado 
por esforços de intermediários, visto que o produtor não consegue desenvolver essa atividade.

Os canais de distribuição evoluem procurando ajustar-se às mudanças macro ambientais. Neste contexto, desde o final dos anos 80 , as empresas vêm descobrindo a extrema importância da gestão da distribuição e da cadeia de suprimentos no alcance de uma vantagem competitiva sustentável e uma verdadeira diferenciação no mercado (ROCHA, 2015).

O presente estudo tem por escopo fazer uma análise de como os canais de distribuição no marketing podem gerar uma vantagem competitiva para os supermercados de pequeno porte. Para consecução de tal intento, foram desenvolvidas três metas específicas: descrever as estratégias de captação de vantagens competitivas aplicadas aos segmentos de supermercados, discutir as diversificações de canais comerciais como recursos estratégicos e formular uma estratégia inovadora para obtenção de vantagens competitivas.

Por se caracterizar como um estudo de caso, a pesquisa tem como objeto de análise o Mercadinho Silva comércio Varejista de mercadorias em geral, com predominância de produtos alimentícios - minimercados, mercearias e armazéns CNPJ: 37.424.262/0001- 93, localizado na rua Domingos de Briegas. Número: 50; CEP: 69090-749, Bairro: Cidade Nova; Cidade: Manaus/AM.

\section{FUNDAMENTAÇÃO TEÓRICA}

$\mathrm{Na}$ discussão que segue, serão oferecidos conceitos teóricos relevantes e a apresentação da evolução do conhecimento na área, dando sustentação à fundamentação teórica do trabalho.

Para Vergara (2016) Denomina-se referencial teórico o capítulo do projeto que tem por objetivo apresentar os estudos sobre o tema, ou especificamente sobre o problema, já realizado por outros autores. 
Na revisão é importante que se use somente os autores do assunto em foco e que possam ser usados na discussão. Esta é uma parte do artigo na qual os resultados obtidos são confrontados com os da revisão e por isso não é interessante colocar autores que não serão utilizados na discussão. (SOARES PEREIRA et al, 2018, p.100).

Tem-se como início da discussão a compreensão do conceito de canais de distribuição, e seu sistema de gestão, incluindo desde os integrantes até as suas respectivas funções. Realizando, posteriormente, uma análise sobre como algumas das principais tendências registradas no setor varejista tem favorecido o crescimento do poder do grande varejo no controle dos canais de distribuição.

\subsection{CANAIS DE DISTRIBUIÇÃO}

Pode-se considerar o processo de distribuição como um agente que dá continuidade à venda, visto que ele é responsável por levar o produto ao consumidor final. Geralmente, o produtor não consegue participar dessa atividade, sendo assim, por necessidade, a mesma é realizada por esforços de intermediários.

Neste contexto, sob um mercado competitivo, Bellin (2016) identifica o canal de distribuição, ou como também conhecido canal de marketing, como uma ferramenta útil para gestão de negócios e extremamente importante no processo da criação de estratégias de marketing de forma sustentável.

O Canal de Marketing é considerado pela Associação Americana de Marketing como uma rede organizada de instituições, que visam realizar atividades capazes de construir uma ligação entre os produtores e os consumidores, a fim de concretizar a tarefa do marketing. Eles são determinados de acordo com a natureza do produto e o tipo de mercado que se tem a intenção de alcançar. Assim, os tipos de canais mais conhecidos e utilizados são: Atacado e Varejo (KOTLER; KELLER, 2012). 


\subsection{CANAIS DE DISTRIBUIÇÃO: DEFINIÇÕES}

De acordo com revisão encontrada em Silva et al. (2012), uma das mais importantes decisões com que se depara o segmento processador refere-se a como organizar seus canais de distribuição.

Uma vez definido o canal de distribuição, é possível identificar o deslocamento físico que os produtos serão submetidos na distribuição. Segundo Dost (2015), os canais permitem a troca de informações e produtos entre fabricantes e clientes e normalmente esta troca ocorre por meio de um ou vários intermediários.

Os canais de distribuição tipicamente incluem três partes principais, a saber: fabricantes, intermediários e usuários finais (KOZLENKOVA et al. 2015).

Oliveira et al (2012) ressalta que os canais de distribuição de marketing são um conjunto de organizações interdependentes, focadas no processo de tornar o produto disponível ou serviço para utilização.

Seu papel é aumentar o nível de rentabilidade dos serviços de distribuição a clientes e/ou consumidores, através de planejamento, organização e controle efetivo de armazenagem e movimentação. Seu objetivo é permitir que os consumidores recebam bens e serviços onde e quando quiserem, em boa condição física e a um custo aceitável (OLIVEIRA et al., 2012, p 25).

Essa função é vista de forma estratégica pelas organizações, pois seus custos são bastante significativos para o negócio, tornando-se um diferencial competitivo em relação aos seus potenciais concorrentes.

\subsection{CANAIS DE DISTRIBUIÇÃO: A INSERÇÃO DO SISTEMA NA EMPRESA}

Fernandes (2012, p.47) afirma que "o propósito do canal de distribuição é satisfazer o usuário final, para isso é de importância crucial que todos os integrantes do canal concentrem sua atenção no usuário final". Os canais de distribuição estão por trás de 
todo produto ou serviço que os consumidores e compradores de corporações adquirem em todas as partes.

Comumente as empresas vendem diretamente seu produto ao consumidor, como, por exemplo, alguns e-commerces. Contudo, quando isso não é possível, a companhia tende a distribuir sua mercadoria ou serviço através de intermediários, como agentes, representantes, corretores, distribuidores, atacadistas e varejistas, dentre outros.

Canais de todos os tipos desempenham um papel importante no sucesso de uma empresa e afetam todas as demais decisões de marketing. Os profissionais de marketing devem julgá-los no contexto de todo o processo pelo qual, seus produtos são feitos, distribuídos, vendidos e atendidos (KOTLER, 2012).

\subsubsection{A EVOLUÇÃO DOS CANAIS DE DISTRIBUIÇÃO NO TEMPO}

Os canais de distribuição evoluem procurando ajustar-se às mudanças macro ambientais. Neste contexto "desde o final dos anos 80 , as empresas vêm descobrindo a extrema importância da gestão da distribuição e da cadeia de suprimentos no alcance de uma vantagem competitiva sustentável e uma verdadeira diferenciação no Mercado" (ROCHA, 2015, p.123).

$\mathrm{Na}$ atualidade, cada empresa desempenha a sua função, na qual são divididas em setores de fabricação, transporte ou armazenagem e, ainda o de venda aos consumidores. Em vista dos custos envolvidos, é muito difícil apenas uma empresa desempenhar todas as funções do canal (SOLOMON, 2016).

Escolher o melhor meio de divulgação e de distribuição para um produto é um dos maiores desafios a serem enfrentados, em razão dos vários canais disponíveis no mercado. Pois caso seja tomado uma escolha errada, todo planejamento de marketing pode ser comprometido. Contudo, o uso desses canais são primordiais para alcançar o consumidor da melhor forma possível e estabelecer parcerias com empresas que sejam capazes de beneficiar seu negócio com lucratividade. 
Dessa forma, a relevância da distribuição no processo de marketing segue-se das atividades do canal que colaboram para satisfação dos clientes. Porém devido aos altos custos envolvidos no fornecimento dos serviços deve-se sempre buscar um equilíbrio entre as necessidades dos consumidores e os custos totais do sistema.

\subsubsection{POR QUE EXISTEM CANAIS DE DISTRIBUIÇÃO}

Os canais de distribuição são muito importantes, nos quais, através de terceiros, possibilitam o maior alcance do produto aos consumidores, proporcionando um aumento nas vendas.

Segundo Andrade (2017) o Canal de marketing, comumente tem como estrutura: fornecedor, atacadista, varejista e consumidor final. Dito isso, o papel do fornecedor consiste em gerar o produto, transformando a matéria prima de acordo com os requisitos de qualidade, enquanto o atacadista tem como função vender os produtos para outras empresas que tenham a intenção de revendê-los. Assim, o varejista é aquele que vende as mercadorias diretamente para o consumidor final, no qual tem o objetivo de consumir o produto pela necessidade.

O canal de marketing também é considerado um custo de oportunidade substancial, sendo uma de suas principais funções, a conversão de compradores potenciais em clientes lucrativos. Assim, não servem apenas para os mercados, mas também para criar o Mercado (KOTLER, 2012).

\subsection{AS FUNÇÕES DOS CANAIS DE DISTRIBUIÇÃO}

Segundo Novaes (2015) o canal de distribuição representa a sequência de empresas que vão transferindo a posse de um produto, desde o fabricante até o consumidor final, portanto, o canal de distribuição de um produto envolverá os seguintes fatores: fabricantes, atacadistas, varejistas e serviços de pós-venda. Segundo o autor em função da estratégia competitiva adotada pela empresa líder, é escolhido um esquema de distribuição específico. 
De acordo com Pride (2015) um dos pontos principais da distribuição de produtos é estabelecer de forma correta e eficiente os canais de marketing, estes canais de distribuição podem ser feitos de maneira direta, no qual os produtos vão diretamente do produtor ao cliente, ou realizados através de intermediários de marketing que por ventura fazem a ligação entre os produtores e outros intermediários ou o consumidor final existente.

Ainda conforme o mesmo autor, entende-se que canais de distribuição são formas de interligar os fabricantes aos consumidores, eles contém as especificidades de cada ramo de atividade, diante disto os diversos tipos de canais de distribuição de produtos devem ser planejados pela empresa, sendo assim é possível a assertividade no controle da qualidade do produto em todas as etapas produtivas podendo agregar um valor superior ao mercado ao entregar um produto na melhor maneira possível ao consumidor final.

\subsubsection{OS CANAIS DE DISTRIBUIÇÃO E A LOGÍSTICA DENTRO DO PROCESSO DE GESTÃO ESTRATÉGICA DO MARKETING}

É percebido de forma ampla e geral, de acordo com os autores citados, que o papel do marketing baseia-se na percepção das necessidades do cliente, portanto torna-se cada vez mais necessário esse estudo mercadológico do ambiente em que se atua, já que a competitividade se amplia e os clientes se tornam cada vez mais exigentes. $O$ entendimento das necessidades dos clientes e a percepção de mudanças gera vantagem competitiva para as organizações.

A essência do marketing se baseia na análise do comportamento do consumidor. Neste contexto, Kotler e Keller (2012) sempre defenderam a importância de o profissional de marketing conhecer muito bem seu público-alvo, com propósito de desenvolver campanhas mais eficientes, capazes de alcançar o maior número de consumidores possível. Deste modo, sob um âmbito competitivo, a captação de novos clientes e a manutenção dos antigos é muito importante para a sobrevivência de uma empresa. 
Solomon (2016) afirmou existir vários fatores, internos e externos, que influenciam a decisão de compra de um cliente, sendo estes os valores, a cultura, os cargos em que ocupam e o estilo de vida que almejam.

\subsubsection{NÍVEIS DE CANAIS DE DISTRIBUIÇÃO}

Segundo Bowersox et al. (2014) refere que as empresas nos últimos anos vêm alterando a forma de estruturar seus canais de distribuição, tendo como foco as atividades competitivas em que consigam segurar por maior tempo a atenção do consumidor e que cada vez mais explorando o uso das tecnologias para a otimização da distribuição ágil e confiável.

Os Canais de Distribuição possuem níveis distintos, e observa-se que tais níveis podem tanto configurar uma considerável vantagem no que se refere à competitividade, quanto uma enorme desvantagem para as empresas, fazendo com que as mesmas percam um tempo valioso ao apresentar os seus produtos e serviços (SOLOMON, 2016).

Os Canais são subdivididos nos níveis, 0, 1, 2 e 3, distintamente caracterizados e com finalidades díspares. No Canal de Nível 0 , as empresas têm contato direto com o consumidor, não se valendo de distribuidoras, nem em atacados e nem em varejo. Esse nível de canal é do tipo híbrido, e determinadas empresas preferem tal nível de canal defendendo que assim, as mesmas se aproximam de seus clientes. Entretanto o nível 0 possui um custo significativo de manutenção, o que muitas das vezes é desconsiderado a priori pela empresa, que precisa oferecer uma grande quantidade de produtos, para continuar com a competitividade e ao mesmo tempo conseguir manter os custos de marketing, de armazenagem e também de venda (ANDRADE, 2017).

Já no Canal de Nível 1, o fabricante efetua a venda de seu produto para um distribuidor de grande porte, que tanto distribui quanto vende, ressaltando que neste caso as vendas são tanto no atacado quanto no varejo, o distribuidor passando a ser o proprietário dos produtos alcança o consumidor final. Uma clientela comum neste nível 
são os atacarejos, que trabalham tanto com 0 atacado quanto com 0 varejo (BOWERSOX et al., 2014).

No Canal de Nível 2, o produto é repassado para um distribuidor, pela indústria, e este distribuidor trabalha com vendas exclusivas para o comércio varejista, e estes que realizam as vendas para o consumidor final. Neste nível os custos inerentes à promoção de vendas ficam a cargo do distribuidor, ou até mesmo do varejista. Isto ocorre porque há uma necessidade de se movimentar o estoque, visto que isto é dinheiro em circulação (ANDRADE, 2017).

E por fim tem o Canal de Nível 3, que é o mais comum pois abarca além do distribuidor, também o representante, varejo e o cliente. Neste nível o custeio com marketing, vendas e distribuição fica sob a responsabilidade de todos os membros do canal, o que ocasiona muitas vezes que o custo seja repassado no valor do produto, atingindo até $25 \%$ do valor do mesmo (SOLOMON, 2016).

Desta forma entende-se que os diferentes níveis de canais de distribuição, assim como os tipos dos mesmos, precisam de uma atenção especial, por se tratar de um dos setores de maior relevância dentro de uma empresa, pois está relacionado a este conhecimento a escolha e a execução da distribuição dos seus produtos, e é imprescindível considerar que a vantagem competitiva de uma determinada empresa está relacionada ao modo utilizado para fazer o produto chegar ao consumidor, seja na qualidade desta distribuição ou na eficiência do transporte.

\subsection{ESTRATÉGIAS COMBINADAS PARA CANAIS DE DISTRIBUIÇÃO}

As estratégias de distribuição são aquelas que consideram a acessibilidade dos consumidores aos produtos ou serviços comercializados por uma empresa. Ao falar de estratégias de distribuição não podemos deixar de conceituar o canal de distribuição, que é o trajeto que o produto deve fazer até chegar no cliente.

Os canais de distribuição são mais do que simples conjuntos de empresas ligadas por vários fluxos. Eles são complexos sistemas comportamentais nos quais pessoas e empresas interagem para atingir 
metas individuais, organizacionais e do canal. Alguns sistemas de canal consistem em interações apenas informais entre empresas livremente organizadas. Outros consistem em interações formais, orientadas por sólidas estruturas organizacionais (KOTLER, 2015, p. 378)

As organizações precisam ser criteriosas quanto a escolha do mix de seus produtos e serviços vendidos para que estejam dentro das necessidades e desejos de seu público-alvo. A gestão de vendas, portanto, deve estar de acordo com o tipo de distribuição pretendida pelos clientes e de como a empresa chegará a eles. Esta decisão conduzirá a empresa a optar entre um canal de distribuição curto e um canal de distribuição longo.

Ao passo que os anos foram se passando, as necessidades dos clientes foram aumentando, tomando atualmente uma proporção nunca vista antes. A todo tempo as empresas buscam se deslocar para regiões mais distantes do planeta em fração de minutos, horas ou poucos dias, conforme a situação e a urgência.

Por esse motivo, os deliverys são procurados e utilizados cada dia mais.

Atualmente o crescimento do setor não se resume a 2020 e a potencialização ocasionada pela pandemia do novo coronavírus. Segundo dados da revista Época, no mundo todo, o setor de home delivery faturou impressionantes 182 bilhões de dólares no ano de 2018.

\section{MATERIAIS E MÉTODOS}

Aragão (2017) define como Método, etapas organizadas sistematicamente a fim de investigar a verdade no estudo de uma ciência para atingir determinada finalidade; e a Técnica como o modo de realizar da maneira mais hábil, segura e perfeita alguma atividade, arte ou ofício.

Diante disso o estudo quanto a metodologia deste trabalho terá como base os variados tipos de pesquisas e fundamentos, a fim de aprimorar e detalhar os principais pontos a serem explorados. 


\subsection{PROCEDIMENTOS METODOLÓGICOS}

Este projeto realizou-se por meio de pesquisas bibliográficas no Google Scholar Acadêmico e coleta de dados, tendo como objetivo identificar artigos, dissertações, livros sobre o tema supracitado.

Segundo Martins e Theóphilo (2016) definem que:

A metodologia científica utilizada como pesquisa bibliográfica constitui o embasamento necessário e básico para a realização de estudos monográficos, ressalvando que o levantamento bibliográfico é a essência do estudo exploratório, devendo ser acompanhado de anotações, registros, notas de aulas.

\subsubsection{QUANTO NA NATUREZA}

Thesaurus (2016) diz que a pesquisa aplicada é dedicada à geração de conhecimento, a fim de solucionar problemas específicos, se propondo a buscar a verdade para uma determinada aplicação prática.

Portanto a abordagem aplicada ao estudo em andamento é a qualitativa em função da busca de analisar, desenvolver e investigar os processos relacionados ao foco do tema abordado. A natureza de pesquisa utilizada será a aplicativa, uma vez que é possível aplicar os instrumentos de estudo na empresa em questão.

\subsubsection{QUANTO AOS FINS}

Quanto aos fins, uma pesquisa pode ser exploratória, descritiva, explicativa, metodológica, aplicada e intervencionista.

O processo descritivo visa à identificação, registro e análise das características, fatores ou variáveis que se relacionam com o fenômeno ou processo. Essa pesquisa pode ser entendida como um estudo de caso em que, após a coleta de dados, é realizada uma análise das relações entre as variáveis para uma posterior determinação dos efeitos resultantes. (PEROVANO, 2014). 
A pesquisa será descritiva onde torna-se possível avaliar a real necessidade, comportamentos e desejos dos consumidores. Dessa forma busca-se novas oportunidades e desenvolvimento, é do tipo exploratória com o objetivo de contribuir para novas perspectivas e hipóteses sobre o objeto ora estudado.

\subsubsection{QUANTO AOS MEIOS}

Trigueiro (2014) afirma que o estudo de caso é uma pesquisa profunda, exaustiva e detalhada de uma unidade de interesse, que pode ser único ou múltiplo e a unidade de análise pode ser uma ou mais pessoas, produto(s), um órgão público.

Quanto aos meios terá como foco o estudo de caso, afim de tornar percetível as informações, coletas e resultados de apenas uma empresa e pesquisas bibliográficas para base e reforço teórico de analise das pesquisas capaz de proporcionar melhor embasamento sobre o tema abordado.

\subsection{CARACTERÍSTICAS DA EMPRESA}

O Mercadinho Silva Comércio Varejista De Mercadorias Em Geral, localiza-se na rua Domingos de Briegas, ํㅜ 50, no Bairro: Cidade Nova da Cidade de Manaus, teve início há 6 anos, ainda no bairro do centro da cidade, recentemente mudou-se para o endereço atual.

Atualmente o Mercadinho Silva, conta com uma estrutura $200 \mathrm{~m}^{2}$, com sala de escritório, além de ambiente para estoque e açougue. Atende em média 300 pessoas diariamente, chegando até o dobro disso em finais de semana. $O$ estabelecimento funciona de segunda feira a sexta feira de $8 \mathrm{~h}$ até às $21 \mathrm{~h}$, Sábado de $8 \mathrm{~h}$ às $15 \mathrm{~h}$ e no Domingo de $8 \mathrm{~h}$ às $12 \mathrm{~h}$, assim classificado como uma empresa de pequeno porte de acordo com a classificação do SEBRAE e da LC 123/2006. O local conta com corredores de mix de vários tipos de produtos, sejam eles, higiene, cereais, limpeza dentre outros, sendo todos os setores identificados. 


\section{RESULTADOS E DISCUSSÕES}

Partindo do princípio onde o objetivo geral deste trabalho busca: Analisar como os canais de Distribuição no marketing podem gerar uma vantagem competitiva para os supermercados de pequeno porte, após pesquisas bibliográficas e estudo de caso foi possível interpretar de forma clara o quanto fica indispensável ter um olhar crítico e minucioso para o setor de marketing em específico, tal medida, quando aplicada de forma estratégica, não somente tem a capacidade de elevar o nível de concorrência como também a rentabilidade do negócio.

Diante dos dados extraídos através das pesquisas realizadas in-loco, é notório que a empresa em estudo apresenta características de foco na maioria de suas áreas funcionais, portanto possui um desempenho insuficiente no setor de marketing, conforme ilustra o gráfico 01: Medição de Desempenho.

Gráfico 01: Medição de desempenho das áreas críticas.

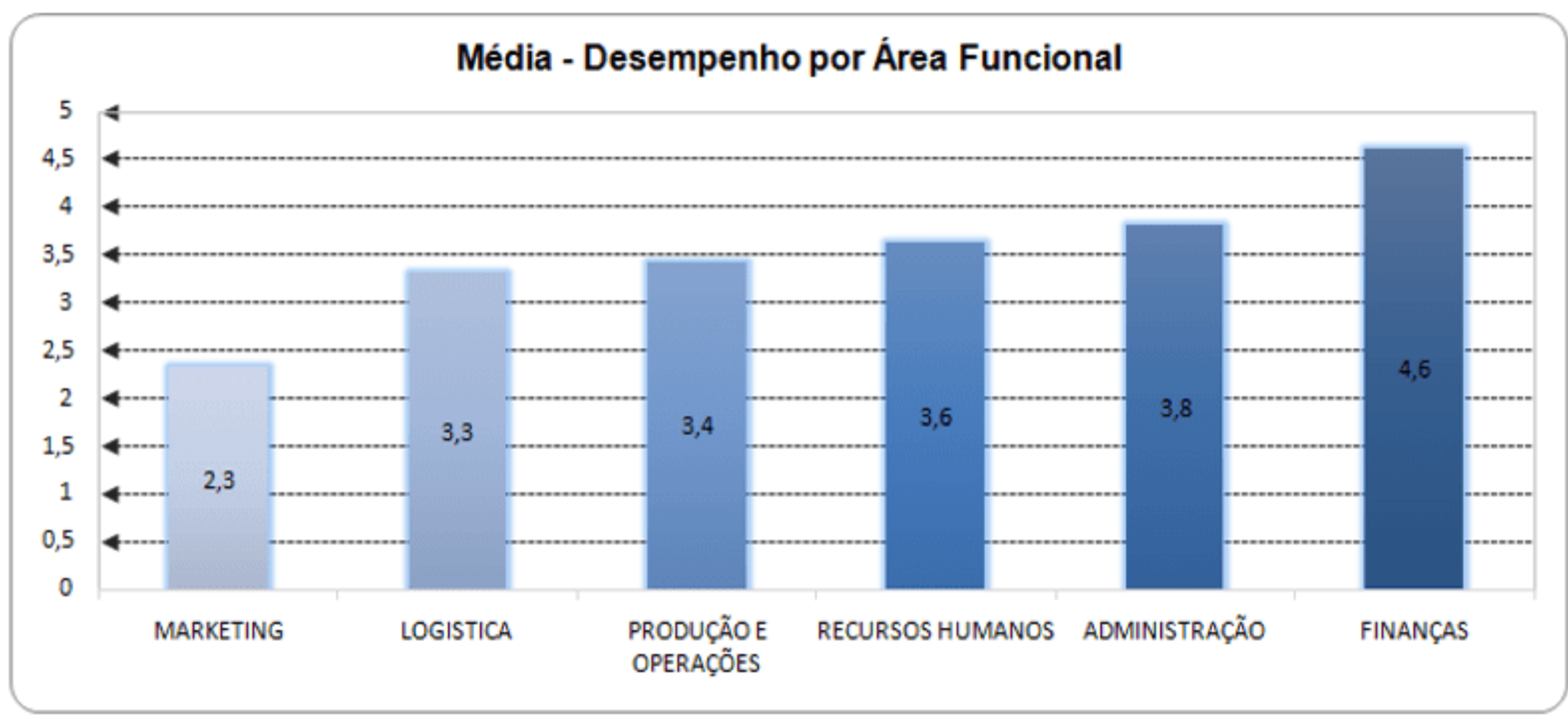

Fonte: Elaborado pelos autores com base na coleta de dados, 2020.

Com o suporte dos fatos que o Gráfico apresenta, identifica-se que o Marketing é uma área pouca desbravada na organização em estudo. Essa inobservância à importância do Marketing causa, além da retenção de seu público alvo, baixa competitividade e redução de faturamento. 
Tem-se como proposta de solução a implementação de estratégias dos canais de distribuição a fim de arrematar o foco nesse setor, alcançar o máximo de clientes possíveis e deixá-los satisfeitos com os serviços ofertados, obtendo assim a fidelização e confiança.

Quadro 1 - Quadro crítico da área funcional

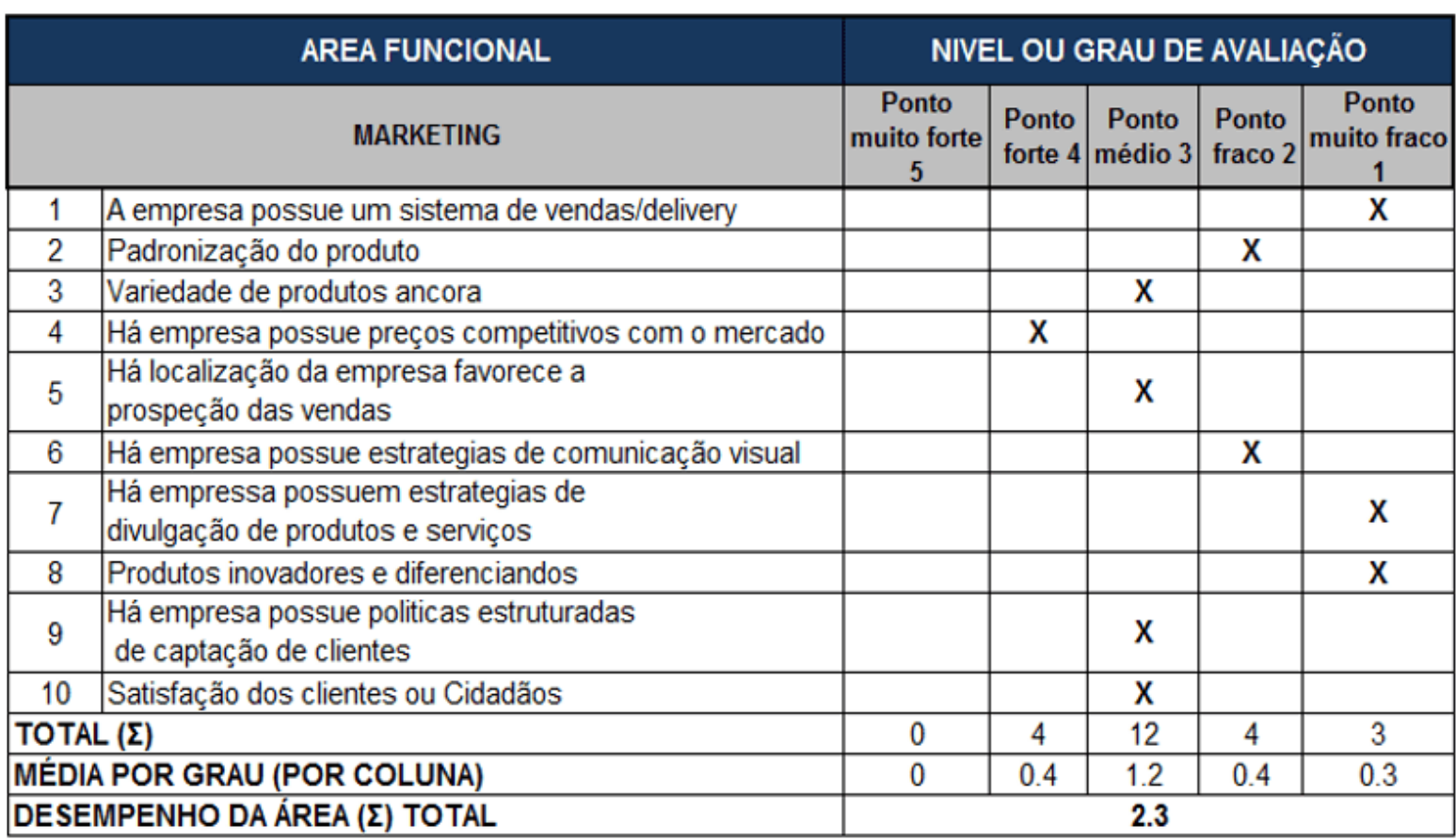

Fonte: Elaborado pelos autores com base na coleta de dados, 2020.

Acerca dos resultados extraídos na coleta de dados realizada, nota-se que a área do Marketing possui os pontos fracos mais críticos Como proposta de solução para melhoria contínua do setor, propomos a seguinte medida: Utilizar os canais de distribuição, implementando um sistema delivery a fim de tornar o Mercadinho Silva competitivo e com serviços diferenciados.

Diante disso, o estudo de caso tem por finalidade os seguintes objetivos específicos: Descrever as estratégias de captação de vantagens competitivas aplicadas aos segmentos de pequeno porte; discutir a diversificação de canais comerciais de distribuição como recurso estratégico. 


\subsection{PLANEJAMENTO DE AÇÕES}

Para desenvolver a proposta de solução de maneira assertiva, foi elaborado um quadro de ações interventivas que será capaz de auxiliar no planejamento e atingimento dos resultados desejados. Acresce ainda que auxiliará resolução do problema proposto que é: Como os canais de distribuição no marketing podem gerar uma fonte de vantagem competitiva para os supermercados de pequeno porte?

Quadro 02: Ações interventivas

\begin{tabular}{|c|c|c|c|c|}
\hline Item & Açäo & Procedentes & Cronologia & Custo \\
\hline 1 & Implantação da ferramenta CRM & $\begin{array}{l}\text { Melhorar gerenciamento das } \\
\text { contas dos clientes }\end{array}$ & 60 dias & RS 300,00/ mês \\
\hline 2 & $\begin{array}{l}\text { Aplicar uma plataforma Digital - APP } \\
\text { site, e-comerce (sistema Delivery) }\end{array}$ & $\begin{array}{l}\text { Atender as necessidades dos clientes } \\
\text { e atingir todos os tipos e publicos }\end{array}$ & 30 dias & RS $1.500,00$ \\
\hline 3 & Contratar serviço Delivery (motoboy) & Para atender as demandas dos pedidos & 20 dias & RS 250,00/ mês \\
\hline 4 & $\begin{array}{l}\text { Elaborar uma montagem do sistema } \\
\text { logistico (rotas, niveis de estoque) }\end{array}$ & $\begin{array}{l}\text { Acompanhar e verificar a veracidade } \\
\text { dos processos }\end{array}$ & 30 dias & $\operatorname{R} \$ 2.300,00$ \\
\hline
\end{tabular}

Fonte: Elaborado pelos autores com base na coleta de dados, 2020

As ações interventivas serão manipuladas e desenvolvidas com a ajuda da ferramenta $5 \mathrm{~W} 2 \mathrm{H}$. Com ela serão medidos, executados e avaliados todos os passos do plano de forma cuidadosa em consonância ao que foi planejado.

Seleme Robson (2012, p.42) afirma: a utilização de tal ferramenta permite que um processo em execução seja dividido em etapas, estruturadas a partir de perguntas com o intuito de serem encontradas as falhas que impedem o término adequado do processo. 


\subsubsection{IMPLEMENTAÇÃO DA FERRAMENTA CRM}

Quadro 03: 5w2h - Implantação da Ferramenta CRM

\begin{tabular}{|c|l|}
\hline \multicolumn{2}{|c|}{ Contratação do sistema delixery (motoboy) } \\
\hline O que? & Implantar a Ferramenta CRM \\
\hline Por quê? & Para melhorar o relacionamento com os clientes \\
\hline Onde? & Mercadinho Silva \\
\hline Quando? & Primeira semana de novembro \\
\hline Quem? & Todos os colaboradores do mercadinho Silva \\
\hline Como? & $\begin{array}{l}\text { Por meio de novas metodologias digitais, dispondo aos } \\
\text { colaboradores treinamentos para o manuseio do mesmo. }\end{array}$ \\
\hline Quanto? & $300,00 /$ mês \\
\hline
\end{tabular}

Fonte: Elaborado pelos autores, 2020.

O processo de implementação de uma ferramenta CRM, trás vários benefícios para o estabelecimento. A organização neste procedimento é prioridade. As informações sobre os clientes ficam à disposição de todos os colaboradores, o que não só agiliza o atendimento para clientes veteranos, como também amplia os canais de comunicação. Assim o feedback dos clientes pode ser organizado, de maneira que traga melhorias ao estabelecimento.

No entanto isso exige reuniões e treinamentos que possibilitem a utilização das novas metodologias digitais.

\subsubsection{APLICAÇÃO DE PLATAFORMAS DIGITAIS- APP, SITES, E- COMMERCE (SISTEMA DELIVERY)}

As plataformas digitais, sejam por aplicativo, sites ou e-commerce (sistema de delivery), são aplicadas de forma gradativa, pois deste modo os colaboradores poderão se habituar ao novo processo.

Lidar com clientes por meio digital é mais complexo do que imaginamos, portanto nesta etapa de implementação, o cuidado com o modo de escrever ou falar com os clientes é essencial, assim como a agilidade no atendimento. 
Quadro 04: 5w2h- Aplicação de Plataformas Digitais- APP, Sites, E-commerce (Sistema Delivery)

\begin{tabular}{|c|l|}
\hline \multicolumn{2}{|c|}{ Contratação do sistema Delivery (motoboy) } \\
\hline O que? & $\begin{array}{l}\text { Aplicar plataformas digitais - App, Sites, E-commerce (sistema de } \\
\text { delivery) }\end{array}$ \\
\hline Por quê? & Para melhorar e aumentar as vendas \\
\hline Onde? & Mercadinho Silva \\
\hline Quando? & Primeira semana de novembro \\
\hline Quem? & Todos os colaboradores do mercadinho Silva \\
\hline Como? & $\begin{array}{l}\text { Propondo treinamento de atendimento ao cliente através das } \\
\text { Mídias implementadas. }\end{array}$ \\
\hline Quanto? & $1.500,00$ \\
\hline
\end{tabular}

Fonte: Elaborado pelos autores, 2020.

Logo todos os colaboradores vão ter que saber lidar com a exposição do estabelecimento, pois assim como esse procedimento traz visibilidade para diversos tipos de clientes, ele também aumenta a responsabilidade daquilo que é escrito ou falado para os clientes, ou seja se o tratamento for bom e eficaz o cliente fará questão de compartilhar e indicar a empresa, no entanto se o caso for inverso, o compartilhamento negativo também ocorrerá e provavelmente em uma escala maior.

\subsubsection{CONTRATAÇÃO DO SISTEMA DELIVERY (MOTOBOY)}

A cada ano que passa, os serviços de entregas se tornam mais essenciais. Afinal, cada vez mais pessoas optam por pedir encomendas em casa. Os pedidos são feitos a restaurantes, mercados, farmácias, lojas virtuais e qualquer outro estabelecimento que oferta esse tipo de serviço.

Logo, para diferenciar um serviço delivery de uma entrega comum, é necessário investimento, tais como, a utilização de embalagens personalizadas ou adesivos que representem a marca. 
Quadro 05: 5w2h - Contratação do sistema delivery (motoboy)

\begin{tabular}{|c|l|}
\hline \multicolumn{2}{|c|}{ Contratação do sistema delivery (motoboy) } \\
\hline O que? & Contratação do Sistema Delivey (motoboy). \\
\hline Por quê? & Para atender a demanda de pedidos realizados. \\
\hline Onde? & Mercadinho Silva \\
\hline Quando? & Primeira semana de Novembro \\
\hline Quem? & A empresa \\
\hline Como? & $\begin{array}{l}\text { Contratando um motoboy regristrado com carteira assinada, que } \\
\text { será funcionario da empresa com horario fixo, salario referente } \\
\text { ao cargo e todos os direitos do trabalhador CLT. }\end{array}$ \\
\hline Quanto? & $\mathrm{R} \$ 250,00 /$ mês \\
\hline
\end{tabular}

Fonte: Elaborado pelos autores, 2020.

\subsubsection{ELABORAR A MONTAGEM DO SISTEMA LOGÍSTICO}

A elaboração de um bom sistema logístico permite a redução de custos de produção e de armazenagem, e possibilita a diminuição do tempo de entrega de seu produto. Assim, o planejamento logístico trata-se de pensar qual a melhor maneira de entregar um produto de qualidade, mais rápido ao cliente, com o menor gasto possível.

Em síntese, o planejamento logístico constitui na criação de novos métodos e estratégias, a fim de reduzir os custos e estabilizar os resultados através da identificação de oportunidades e otimização dos processos.

Para criar um planejamento correto para sua empresa, é necessário fornecer ao seu cliente produtos de boa qualidade e de baixo custo, tem que haver compromisso de entregar o produto exigido com rapidez e num estado que corresponda às expectativas do cliente. 
Quadro 06: 5w2h - Elaborar a montagem do sistema logístico.

\begin{tabular}{|c|l|}
\hline \multicolumn{2}{|c|}{ Elaborar a montagem do sistema logistico } \\
\hline O que? & Elaboração da montagem de um sistema logistico \\
\hline Por quê? & $\begin{array}{l}\text { Para reduzir custos de produção e de armazenagem e aumentar a } \\
\text { velocidade de entrega de seu produto }\end{array}$ \\
\hline Onde? & Mercadinho Silva \\
\hline Quando? & Primeira semana de Novembro \\
\hline Quem? & Todos os colaboradores do mercadinho Silva \\
\hline Como? & $\begin{array}{l}\text { Tendo fornecedores confiaveis, uma boa gestão de estoque, transporte } \\
\text { eficiente, embalagens corretas e prazos cumpridos corretamante. }\end{array}$ \\
\hline Quanto? & R\$ 2.300,00 \\
\hline
\end{tabular}

Fonte: Elaborado pelos autores, 2020.

Dito isto, várias são as oportunidades que a empresa pode explorar para implementar um sistema logístico efetivo. $O$ atendimento ao cliente pode contar com formulários padronizados para realização dos pedidos, os quais disponham dos campos necessários para o processamento correto: produto, pesquisa do item solicitado no estoque, endereço para entrega, ponto de referência, forma de pagamento e previsão para entrega (em minutos). Também deve ser observada a organização da fila de pedidos por ordem de fechamento para evitar atrasos nas entregas. Contato telefônico com os entregadores para retirada de dúvidas e contato com o cliente são alguns exemplos de melhorias e ajustes que também devem ser realizados.

Ao adquirir o conhecimento sobre o histórico das necessidades dos clientes e realizar uma análise objetiva e analítica dos feedbacks recebidos é possível mensurar o grau de satisfação deles e aferir o nível de sucesso do sistema logístico como um todo.

O planejamento logístico é o suporte para toda a cadeia de suprimentos, desde a compra do produto, transporte, armazenamento no estoque e entrega ao consumidor final. É o resultado aos entraves encontrados pelas empresas e a solução para os clientes que desejam ter produtos e serviços de qualidade e que satisfaçam suas necessidades no mais curto prazo possível. 
Problemas existem para serem resolvidos e cada obstáculo encontrado é um convite à inovação e à utilização da criatividade em sua resolução.

\section{CONSIDERAÇÕES FINAIS}

A pesquisa teve como objetivo geral analisar como os canais de distribuição podem gerar uma vantagem competitiva para os supermercados de pequeno porte. Foi constatado que o objetivo geral foi atendido porque o trabalho conseguiu demonstrar, de forma efetiva, a importância de um olhar crítico sobre o marketing, uma vez que este aumenta o nível de concorrência e a rentabilidade do negócio quando aplicado corretamente.

Ao retomar os objetivos específicos estabelecidos inicialmente, a presente pesquisa possibilitou descrever as estratégias de captação de vantagens competitivas aplicadas aos segmentos de pequeno porte. Dessa forma, o primeiro objetivo específico foi atendido, pois o trabalho utilizou estratégias como a implantação da ferramenta CRM, que ajuda a ter melhor trato com o cliente. O segundo objetivo específico estabelecido foi discutir a diversificação de canais comerciais de distribuição como recurso estratégico. Este também foi alcançado; haja vista que foi implementada a plataforma de delivery, que ajuda o cliente a realizar o pedido de forma rápida e segura.

Conclui-se, portanto, que a elaboração de um plano de marketing deve ser bem planejada, considerando as diversas variáveis. isso resultará em ótimas oportunidades para a empresa e possibilitará alternativas para manter e fidelizar os clientes; além de fomentar o crescimento e o sucesso no mercado. É importante salientar que a elaboração do estudo foi baseada em entrevistas realizadas com o dono e os funcionários do Mercadinho Silva. O estudo foi complementado com pesquisas bibliográficas, as quais foram fundamentais na elaboração do presente trabalho.

Não obstante as adversidades enfrentadas, foi possível alcançar os objetivos propostos para este estudo. Concluímos que o proprietário do Mercadinho Silva 
compreendeu a relevância do investimento em canais de distribuição. Com base nos resultados do estudo ora apresentado, ficou patente a necessidade de cumprir o propósito do estabelecimento que é satisfazer as expectativas dos clientes, atrair e fidelizar consumidores e firmar-se como a melhor opção de local de compra.

\section{REFERÊNCIAS}

ANDRADE, D. F. Marketing do produto volume 1/Organizador Darly Fernando Andrade - Belo Horizonte MG: Poisson, 2017.

ARAGÃO, J. W.M. Metodologia Científica. [recurso eletrônico] / José Wellington Marinho de Aragão, Maria Adelina Hayne Mendes Neta. - Salvador: UFBA, Faculdade de Educação, Superintendência de Educação a Distância, 2017.

BELLIN, H. Para qual canal de marketing é certa sua empresa? Journal of Marketing. Channels, 2016.

BOWERSOX, D. J.; CLOSS, D. J.; COOPER, M. B. Gestão Logística na Cadeia de Suprimentos. Porto Alegre: AMGH, 2014.

DOST, F. Uma rede causal não linear de estrutura do sistema de canais de marketing. Journal of Retailing e Serviços ao Consumidor, 2015.

FERNANDES, K. S. Logística: fundamentos e processos / Kleber dos Santos Fernandes. - 1.ed. rev. - Curitiba, PR: IESDE Brasil, 2012.

KOTLER, P. Administração de marketing / Philip Kotler, Kevin Lane Keller; tradução Sônia Midori Yamamoto; revisão técnica Edson Crescitelli. - 14. ed. - São Paulo: Pearson Education do Brasil, 2012.

KOTLER, P.; KELLER. K. L. Administração de marketing. 12. ed. São Paulo: Pearson Prentice Hall, 2012. 
KOTLER, P. Princípios de marketing / Philip Kotler, Gary Armstrong; tradução Sabrina Cairo; revisão técnica Dilson Gabriel dos Santos e Francisco Alvarez. - 15. Ed. - São Paulo: Pearson Education do Brasil, 2015.

KOZLENKOVA, I. V.; et al. O papel dos canais de marketing na cadeia de suprimentos Gestão. Journal of Retailing, v. 91, n. 4, pág. 586-609, 2015.

MARTINS, G. de A.; THEÓPHILO, C. R. Metodologia da investigação científica para ciências sociais aplicadas. 3. ed. São Paulo: Atlas, 2016.

NOVAES, A.G. Logística e Gerenciamento da Cadeia de Distribuição. 4aa ed. Rio de Janeiro: Elsevier, 2015.

OLIVEIRA, B. (Organizador). Gestão de marketing - São Paulo: Pearson Prentice Hall, 2012.

PEROVANO, D.G. Manual de Metodologia Científica, Curitiba, Juruá Editora 2014.

PRIDE, W. M.; F. O. C. Fundamentos de marketing: conceitos e práticas. 6. ed. São Paulo: Cengage Learning, 2015.

ROCHA, R. A. Administração de Marketing / Rudimar Antunes da Rocha e Allan Augusto Platt. - 3. ed. - Florianópolis: Departamento de Ciências da Administração/UFSC, 2015.

SELEME,R.Controle da qualidade: as ferramentas essências [livro eletrônico] / Robson Seleme, Humberto Staldler-( Série Administração da produção) Curitiba : lbpex,2012.

SILVA, V. L. S., AZEVEDO, P. F. \& NEVES, M. F. Franchising, valor de marca e canais de distribuição. In V. L. S. Silva \& P. F. Azevedo (Orgs.), Teoria e prática da franchising: estratégia e organização de redes de franquias (cap. 1.). São Paulo: Atlas 2012. 
SOARES, P. A ... [et al.]. - 1. ed. - Santa Maria, Metodologia da pesquisa científica [recurso eletrônico] / RS: UFSM, NTE, 2018.

SOLOMON, M. R. O comportamento do consumidor.11. ed. Porto Alegre: Bookman, 2016.

THESAURUS, Metodologia da Pesquisa Científica: teoria e prática - como elaborar TCC". Brasília: 2016.

TRIGUEIRO, R.M; Metodologia científica / Rodrigo de Menezes Trigueiro, Marilucia Ricieri, Gisleine Bartolomei Fregoneze, Joacy M. Botelho. - Londrina: Editora e Distribuidora Educacional S.A., 2014.

VERGARA, S. C. Projetos e relatórios de pesquisa em administração / Sylvia Constant Vergara. - 16. ed. - São Paulo: Atlas, 2016.

Enviado: Outubro, 2020.

Aprovado: Novembro, 2020. 